\title{
"Não matou ninguém, mas deixou todo mundo meio torto": trabalho, educação e infância desde a vitivinicultura de Videira, Santa Catarina, Brasil $^{1}$
}

\author{
Soraya Franzoni Conde ${ }^{2}$ \\ Natália Palhoza ${ }^{3}$
}

\begin{abstract}
Resumo
Este artigo tem como foco o trabalho realizado por crianças ítalo-descendentes em pequenas propriedades rurais familiares, no Município de Videira, SC. O objetivo é refletir sobre a relação entre o trabalho infantil na vitivinicultura e a educação. Foram desenvolvidas entrevistas semiestruturadas com seis idosos, com idade entre 58 e 102 anos, cujas infâncias estiveram atreladas à produção de uvas e vinhos artesanais nas pequenas propriedades de suas famílias. Também foi desempenhada investigação documental e bibliográfica no Museu do Vinho Mário de Pellegrin. Os dados foram analisados a partir dos pressupostos do materialismo dialético e da Teoria Histórico-Cultural (MARX, 2017; THOMPSON, 1987; VYGOTSKY, 1991, 2004). A pesquisa revela que as crianças estavam inseridas em diversas fases do processo produtivo vitivinícola nas pequenas propriedades. As crianças trabalhavam junto aos seus familiares em longas jornadas semanais. $\mathrm{O}$ trabalho infantil extrapolava o parreiral e se fazia presente nas tarefas domésticas, no cuidado com os animais e no manejo dos demais cultivos da propriedade. A atividade de trabalho era prioritária e competia com o tempo de escola, contribuindo significativamente para a evasão escolar. O tempo de brincadeiras também era limitado, configurando-se como exceção na vida das crianças.
\end{abstract}

Palavras-chave: Trabalho infantil, educação, vitivinicultura.

"It didn't kill anyone, but it left everyone half cracked": work, education and childhood since viticulture in Videira, Santa Catarina, Brazil

\begin{abstract}
This article focuses on the childhood of Italian descendants in the municipality of Videira, SC, in small rural properties that produce grapes and handmade wines. The objective is to reflect on the relationship between child labor in viticulture and education. A semi-structured interview was carried out with six elderly people between 58 and 102 years, whose childhoods were linked to the production of grapes and artisanal wines in the small properties of their families. In addition, documentary and bibliographic research was carried out at the Museu do
\end{abstract}

\footnotetext{
${ }^{1}$ Este artigo é parte das pesquisas desenvolvidas no âmbito do projeto "Repositório de Práticas Interculturais: Proposições para Pedagogias Decoloniais", desenvolvido junto ao Programa de Internacionalização Capes/PRINT/UFSC. Parte da coleta dos dados foi feita durante o estágio da primeira autora deste artigo, professora visitante na City University of New York, com bolsa Capes/PRINT/UFSC, cujo projeto de pesquisa matriz recebe apoio financeiro da Fundação de Amparo à Pesquisa e Inovação do Estado de Santa Catarina (Fapesc), Edital 06/2016.

${ }^{2}$ Doutora em Educação pela UFSC e Pós Doutora em Psicologia e Educação Urbana pela City University of New York. Professora dos Programas de Pós-Graduação em Educação (PPGE) e em Serviço Social (PPGSS) da UFSC. Pesquisadora do Núcleo de Estudos sobre as Transformações no Mundo do Trabalho (TMT/UFSC) onde coordena o Grupo de Estudos Trabalho, Educação e Infância. Membro Histedbr. Orcid: https://orcid.org/00000002-5271-6479. E-mail: sorayafconde@gmail.com.

${ }^{3}$ Mestra em Educação (2019) pelo Programa de Pós-Graduação em Educação da Universidade Federal de Santa Catarina (PPGE/UFSC). Participa do Núcleo de Estudos sobre as Transformações no Mundo do Trabalho (TMT/CED-CFH/UFSC) e do Grupo de Estudos sobre Trabalho, Educação e Infância (GETEI). Atualmente é professora no Instituto Federal Catarinense, campus Araquari, nos cursos de Licenciatura em Química e Licenciatura em Ciências Agrárias. Orcid: https://orcid.org/0000-0002-2714-1319. E-mail: nataliapalhoza@hotmail.com.
} 
Vinho Mário de Pellegrin. The data were analyzed based on the assumptions of dialectical materialism and historical cultural theory (MARX, 2017; THOMPSON, 1987; VYGOTSKY, 1991; 2004). The research reveals that children were inserted in different phases of the wine production process in small properties. The children worked with their families on long weekly hours. Child labor went beyond the vineyard and was present in domestic chores, in the care of animals and in the management of other crops on the property. Work activity was a priority and competed with school time, contributing significantly to school dropout. Playing time was also limited, making it an exception in the lives of those children.

Keywords: Child labor, education, viticulture.

\section{Apresentação}

O objetivo deste artigo é refletir sobre a relação entre o trabalho infantil na vitivinicultura e a educação no município de Videira, Santa Catarina. Ele é parte de uma pesquisa de mestrado em Educação da Universidade Federal de Santa Catarina, realizada entre 2017 e 2019 com ítalo-descendentes, filhos ou netos de migrantes oriundos do Rio Grande do Sul, instalados em pequenas propriedades rurais e produtoras de uvas no município.

Foram desenvolvidas entrevistas semiestruturadas com seis idosos, com idade entre 58 e 102 anos, cujas infâncias passaram-se em pequenas propriedades videirenses produtoras de uva. Também foi desenvolvida pesquisa documental e bibliográfica no Museu do Vinho Mário de Pellegrin. Consideramos o vasto acervo de peças relacionadas à vitivinicultura, a exposição de longa duração, o acervo fotográfico digitalizado, a coleção de livros sobre memórias de famílias e localidades da biblioteca e, por fim, os resultados da pesquisa Pioneiros da uva e do vinho (HOELLER; ZAGO; SINZKER, 2018), desenvolvida pela instituição. Os dados foram analisados a partir dos pressupostos do materialismo históricodialético, que entende o ser humano como a síntese de múltiplas determinações, cuja constituição se dá em meio a práticas sociais compartilhadas e que expressam a relação dialética entre passado, presente e futuro.

Conforme torna-se evidente, a pesquisa busca compreender a relação entre o trabalho infantil e a educação a partir da memória, pois todos os instrumentos de coleta de dados tiveram a finalidade de nos colocar diante de um tempo que não pode ser diretamente observado por nós, mas apenas aproximado, por meio de relatos escritos ou falados, de registros fotográficos e de objetos de museu. 
61 Polyphonía, v. 32/2, jul./dez. 2021

Entendemos memória, a partir de Vygotsky (1991), como uma função psicológica superior exclusivamente humana e fundamental para a criação, conservação e reprodução de signos. Ela desempenha papel indispensável na humanização dos indivíduos, por ser um ato consciente e intencional. A partir de Pollak (1992) e Bosi (1994), entendemos que a memória possui também determinações sociais, tendo em vista que ela se constrói e se interpreta a partir da conversa com outros indivíduos. A memória também apresenta como característica a seletividade, pois os seres humanos não conseguem se lembrar de todos os detalhes de todos os momentos vividos. Todavia, os referidos autores apontam a relevância significativa da memória como fonte de pesquisa, desde que contextualizada e relacionada a outras informações.

O texto está organizado da seguinte forma: primeiramente, apresentamos o contexto da vitivinicultura em Videira, SC; na sequência, evidenciamos o trabalho infantil na produção de uvas e de vinhos artesanais nas pequenas propriedades videirenses; posteriormente, refletimos sobre aspectos referentes à educação, ao brincar e à cultura, relacionados ao trabalho infantil vivenciado pelos participantes desta pesquisa.

\section{A "bebida dos deuses" no território catarinense}

Ainda que o vinho seja chamado popularmente de 'bebida dos deuses', sua existência nada mais é do que um produto do trabalho humano. A descoberta da bebida fermentada ocorreu quando os povos mesopotâmicos tentaram armazenar frutas do gênero vitis em vasilhas de cerâmica, em uma data estimada entre 9000 e 4000 a.C. Desde então, a bebida foi comercializada entre diferentes povos e tornou-se presente em sincretismos religiosos, além de contar com aprimoramento no seu processo produtivo - tanto nas técnicas de plantio, colheita e vinificação quanto na seleção de variedades mais doces de uva (STANDAGE, 2005).

No Brasil, a produção do vinho tem relação direta com a introdução de colonos italianos no Rio Grande do Sul, a partir de 1870. As famílias italianas iniciaram a produção de videiras tão logo se instalaram nas terras gaúchas, adaptando-se às variedades americanas, como a Isabel, que já haviam sido introduzidas no país cerca de meio século antes (RODRIGUES, 2008). Aos poucos, as famílias aumentaram suas pequenas produções e passaram a gerar uma quantidade de vinho excedente. Dessa forma, a bebida se tornou uma 
mercadoria comercializada com colônias de imigrantes de outras nacionalidades e com outras regiões do país. No estado gaúcho, ainda no final do século XIX, algumas das pequenas produções familiares se transformaram em indústrias vinícolas (RODRIGUES, 2008).

A passagem da produção artesanal e familiar para a industrial contou com a adesão de maquinário específico, além de uma reorganização nos métodos de fabricação e nas relações de trabalho. As pequenas propriedades rurais - que antes desempenhavam todo o processo, do plantio da uva à vinificação - foram sendo resumidas a produtoras de matéria-prima para a indústria. Ainda que as pequenas propriedades continuassem produzindo vinho artesanal, não era essa atividade que lhes garantia a subsistência.

Todo esse processo que aconteceu no Rio Grande do Sul teve forte impacto no meiooeste de Santa Catarina, a partir do fim da primeira década do século XX, quando colonos que residiam no estado gaúcho passaram a migrar para o solo catarinense. Devido ao potencial econômico que o setor apresentava no Rio Grande do Sul, os migrantes levavam para Santa Catarina os germes da vitivinicultura: instrumentos de cultivo, mudas de vinhas, métodos e equipamentos para colheita e vinificação, assim como a própria indústria de produção de vinhos e de barris. É nesse sentido que parte importante da história do território atualmente determinado como Município de Videira, no Vale do Rio do Peixe, confunde-se com a história da migração dos ítalo-descendentes, com o plantio de uvas e com a produção de vinhos.

Segundo informações do Museu do Vinho Mário de Pellegrin (2014), já em 1913 antes da intensificação do movimento migratório para a região -, foi registrado o plantio das primeiras cepas de uva nas terras que viriam a ser Videira. Apenas alguns anos depois, em 1919, instalou-se a primeira indústria de vinhos na localidade. Isso nos mostra que o plantio de uvas nas pequenas propriedades locais nasceu atrelado à produção industrial de vinhos, que já dava seus primeiros passos na região àquela época. Além disso, devido à existência de ferrovias, os produtores também vendiam suas uvas como matéria-prima para as fábricas de suco paulistas. O setor vitivinícola representava uma parcela fundamental da economia e, em virtude disso, influenciou a emancipação política do município, no ano de 1942 (MUSEU DO VINHO, 2014). 
63 Polyphonía, v. 32/2, jul./dez. 2021

"Não matou ninguém, mas deixou todo mundo meio torto"

Os participantes desta pesquisa relataram memórias de trabalho infantil na vitivinicultura, em diferentes atividades do processo produtivo, nas pequenas propriedades familiares em que residiram. São exemplos disso a sulfatagem, a limpeza do parreiral, a colheita e a produção artesanal de vinhos. É interessante frisar que eles não possuem memórias relacionadas ao plantio de videiras quando crianças, tendo em vista que as propriedades de suas famílias já possuíam parreirais desde que seus pais ou avós se instalaram no local. Como as mudas permaneceram produzindo por longos períodos, acabaram por atravessar gerações.

Nas pequenas propriedades familiares, um trabalho frequentemente delegado às crianças era a limpeza do parreiral, com a utilização de enxadas. A atividade era recorrente ao longo do ano todo e se repetia sempre que necessária, tendo em vista que um parreiral em meio ao mato era considerado desleixado; e o seu proprietário, uma pessoa sem capricho. Assim, "não podia ter nem um matinho" (informação oral). ${ }^{1}$ Algumas famílias conseguiam utilizar arado e bois em algumas partes do parreiral para facilitar a limpeza, porém sempre sobravam espaços em que o arado não alcançava, o que tornava indispensável a atividade manual e dispendiosa de carpir.

Tão logo completavam 6 ou 7 anos, as crianças ganhavam dos pais uma enxada pequena, menor do que a usada pelos adultos - cujo peso e tamanho impossibilitavam seu manejo pelas crianças. $\mathrm{O}$ instrumento de trabalho era fabricado de modo proporcional a quem iria utilizá-lo: "pra cada tamanho de piazada, o pai tinha as enxadinhas" (informação oral). ${ }^{2}$ Isso demonstra que havia uma adaptação da ferramenta ao corpo dos trabalhadores mirins, para que estes conseguissem acompanhar os demais familiares no trabalho de carpir.

Um dos entrevistados acrescentou que tal função era executada sempre com os pés descalços. Mesmo tendo ganhado seu primeiro calçado aos dez anos, o trabalho na roça continuou sendo feito com os pés desprotegidos, já que o sapato era usado somente em passeios. Pela falta de proteção ao carpir, ele contou que frequentemente cortava os dedos ou arrancava as unhas com a enxada. Os cortes ocasionados eram tratados na própria casa, com banhos de ervas e sal. Assim, o entrevistado alega que sentia 'pavor' de carpir sob o parreiral, mas isso não quer dizer que ele pudesse recusar o serviço - eram os pais que decidiam qual e 
quem faria cada função, independentemente da vontade dos filhos. Todos os indivíduos precisavam trabalhar para garantir a subsistência da própria família.

A chegada dos agrotóxicos, na década de 1970, representou uma revolução no processo produtivo vitivinícola e veio a substituir a atividade de carpir. Resultou em uma diminuição do tempo de trabalho dispendido com a produção das uvas, revelando, dessa forma, a atuação da ciência em benefício do capital. Porém as famílias não tinham informações sobre os efeitos dos agrotóxicos na natureza, nas parreiras e na saúde humana, manuseando os produtos sem a proteção adequada. Nesse sentido, um dos participantes contou que, antes dos dez anos de idade, já trabalhava com seu pai puxando mangueiras de veneno na parreira, "sem nada [de proteção]! Às vezes sem chapéu na cabeça!" (informação oral) ${ }^{1}$.

Existem registros de acidentes relacionados ao manuseio de agroquímicos por crianças - como este a seguir, descrito no livro de um médico da cidade:

Passava o ano de 1975. O menino Adir auxiliava o pai, em um domingo, na arrumação do pátio e do pequeno pomar. No momento em que o pai colocou uma lata do agrotóxico Folidol no degrau da escada do paiol, Adir apanhou-a e bebeu um pequeno gole. Logo começou a se sentir mal, com dor de cabeça, opressão no peito, pupilas fechando-se em miose, vômitos, salivação e dor abdominal. Envenenamento por tóxico organofosforado. Com a cooperação de mais dois colegas, fiz aplicações repetidas de atropina em injeções intramusculares, conforme era recomendado, mas o menino morreu na mesma tarde (KARAN, 2000, p. 119).

Para além do risco de ingestão letal de agrotóxico - como o relato denota -, havia ainda formas de contaminação menos perceptíveis, como a absorção do produto por vias dérmicas ou respiratórias, com efeitos agudos e crônicos (SILVA et al., 2005). Segundo Castro (2009), devido às especificidades do próprio corpo em desenvolvimento, as crianças são mais afetadas pela intoxicação com agrotóxicos. De forma geral, os agrotóxicos aumentam o risco de adoecimento e morte como decorrência do trabalho, de forma imediata ou não.

Evidencia-se que a troca do estafante trabalho com a enxada pelos agrotóxicos veio associada aos altos riscos de intoxicação e danos à saúde, de curto a longo prazo. Esses efeitos perigosos nem sempre eram percebidos pelos produtores, devido à falta de sintomas imediatos. Trocava-se um veneno por outro, conforme a analogia de um participante: 
Entrevistado: Era só o que quase usava, sulfato, antigamente. O maior veneno que tinha antigamente, que nós usava, era a dita enxada.

Pesquisadora: Enxada?

Entrevistado: Porque era um veneno para nós. [risos]

Entrevistada: Não matou ninguém. [risos]

Entrevistado: Não matou ninguém, mas deixou todo mundo meio torto, porque carpia o dia inteiro. Era tudo carpido. (informação oral). ${ }^{1}$

Sendo o veneno uma "substância que mata seres vivos ou os torna doentes" (VENENO, 2018), como vimos no exemplo anterior, do menino Adir, a enxada, ainda que não fosse substância venenosa, também poderia ser considerada 'veneno', tendo em vista que oferecia sérios riscos aos envolvidos na produção vitivinícola, especialmente ao trabalho que se iniciava ainda na infância.

As crianças também estavam inseridas no processo de sulfatagem das parreiras, conforme fica evidente a seguir:

\begin{abstract}
Outra lembrança viva na memória dos irmãos mais velhos é que estavam quase sempre descalços ou de pé no chão. Minha mãe - Verginia - nos relatou que em uma ocasião ela e os tios foram levar sulfato para o nono que estava sulfatando as parreiras. Eles deixaram os galões com o produto próximo a um tronco de pinheiro que estava caído no chão e sentaram para descansar. De repente ela sentiu que alguma coisa estava passando por baixo do seu pé e quando olhou viu uma cobra. Chamou o nono que com um pau matou a serpente. Era uma jararaca. O nono chamava de cruzeira porque tinha uma cruz na cabeça. Segundo ele, era uma cobra muito venenosa, muita sorte não tinha acontecido o pior (SANTOS, 2012, p. 53-54).
\end{abstract}

As crianças não estavam submetidas apenas ao risco do trabalho na sulfatagem das parreiras mas também ao risco de acidente com animais peçonhentos. A falta de calçados também intensificava a incidência de picadas de serpentes. Esse tipo de acidente dificilmente é relacionado ao trabalho, apesar de se configurar como uma consequência direta do ambiente em que as atividades laborais ocorrem (SILVA et al., 2005).

Dentre todos os processos do manejo da uva na pequena propriedade rural, o mais marcante na memória de infância dos entrevistados foi a colheita da uva. A atividade era desempenhada manualmente por todos os familiares, em jornadas diárias ao longo de um mês. Geralmente a retirada dos cachos dos pés era desempenhada por mulheres, idosos e crianças, que se utilizavam de cestas de vime para acomodar os frutos. Depois disso, a uva era transferida para caixas e, na sequência, levada para fora do parreiral, manualmente. 
As crianças também participavam do transporte da uva para fora do vinhedo, levando caixas vazias de volta para a parreira com o auxílio de um carrinho de madeira. As responsabilidades nessa função cresciam com a idade e a força: "Daí, conforme a piazada ia crescendo, então [...], pra levar de volta, carregava uma caixa em cima do carrinho e levava. Daí os maiores carregavam duas, três, dependendo da idade" (informação oral). ${ }^{1}$

A quantidade de vinhas produzidas era importante para os pequenos produtores, porque a uva era mensurada por quilogramas, resultando em rendimento proporcional. As famílias se esforçavam para não desperdiçar os frutos e incumbiam as crianças muito pequenas - que ainda não alcançavam as vinhas - de recolher do chão os grãos que caiam durante a colheita. Segundo um entrevistado, as crianças “ajuntavam grão por grão. [...] Não podia perder nenhum grão!" (informação oral). ${ }^{1}$ A atividade era policiada pelos adultos responsáveis, conforme evidencia-se a seguir:

\footnotetext{
Se escapava um cacho no chão, a piazada tinha que ajuntar. [...] E era tarefa. E os velhos eram brabos ainda. [...] Tinha uns tios lá [pausa]. Naquele tempo não era o pai e a mãe que mandavam nos filhos; era o tio o cara que comandava a colheita da uva, que reunia as famílias, naquele tempo. Colhiam [pausa], aí caía no chão, $e$ naquele tempo, normalmente [pausa], principalmente a minha raça lá [sobrenome da família], era tudo meio radical. [...] Pontapé na bunda, esse tipo de coisa, empurravam. [As crianças] iam atrás [dos adultos que colhiam]. Vinham vindo e de vez em quando o cara dava uma conferida: - "Ó, sobrou uva pra trás no chão, lá. Volta lá ajuntar!". (informação oral). ${ }^{2}$
}

Nesse relato, nota-se a troca de serviços entre famílias vizinhas, um tipo de relação de trabalho comum naquele contexto (MUSEU DO VINHO, 2014; BALDISSERA et al., 2016). A colheita exigia mais força de trabalho do que as famílias dispunham individualmente, então dois ou mais grupos se reuniam e colhiam as uvas de forma coletiva. Não havia um pagamento em dinheiro, mas sim a troca de horas trabalhadas. Isso incluía o trabalho das crianças. Para estas, a relação de trabalho adquiria um caráter análogo à de patrão-empregado: mesmo sem remuneração, seguiam um ritmo que independia delas mesmas, executavam tarefas repetitivas e respeitavam uma hierarquia superior à figura paterna, já que o chefe era o dono da terra.

Segundo o depoimento, a violência era a estratégia usada para submeter as crianças ao trabalho. Considerando a distância histórica, essa forma de tratamento aos trabalhadores mirins nos remete ao período da Revolução Industrial, em que as crianças eram disciplinadas 
67 Polyphonía, v. 32/2, jul./dez. 2021

através de ações violentas por parte dos patrões (MARX, 2017). Todavia, se na Revolução Industrial as crianças eram obrigadas a acompanhar o ritmo das máquinas, no contexto analisado, tinham que encalçar os adultos.

Pelo trabalho na colheita no parreiral, alguns entrevistados contam que recebiam um fiorin: "nós ganhávamos um fiorin naquele tempo por dia, só. E ainda nós pensávamos que era bastante. Imagina, se ficava trinta dias, então era trinta [pausa]. Ih, mas então parecia que era rico!"' (informação oral). ${ }^{3} \mathrm{O}$ fiorin remetia à memória dos agricultores, pois, em sua origem italiana, tinha o sentido da forma genérica do dinheiro. A aparente riqueza causada pelo dinheiro recebido contrastava com a realidade do intenso trabalho dentro da propriedade familiar, que não era diretamente remunerado.

As filhas mais velhas das famílias, em períodos de colheita ou não, assumiam a tarefa de cuidar dos irmãos menores. Dessa forma, liberavam a mãe para o trabalho no parreiral ou para os outros afazeres domésticos. A mulher era, geralmente, a responsável pelo almoço de todos os trabalhadores envolvidos com a colheita da uva na propriedade familiar - filhos, marido, vizinhos, contratados.

A força de trabalho infantil também era empregada em processos rudimentares, como a moagem, na qual, por tradição, as uvas eram esmagadas com os pés das mulheres e das crianças (MUSEU DO VINHO, 2014; BALDISSERA et al., 2016). Uma entrevistada recordou que seu pai “[...] fazia um caixote, assim, com tudo, ripa, assim, e jogava dentro a uva [...]. E daí, com os pés, as crianças que pisava, né? [...] [As crianças] gostavam! Um pouco um, um pouco o outro" (informação oral). ${ }^{3}$

Para os entrevistados, as memórias de trabalho infantil não se resumiram à vitivinicultura. Junto aos seus familiares, eles carpiam as plantações de milho; usavam enxadas para cobrir sementes de trigo; carregavam milho seco em cestos até a carroça; coletavam ovos; cortavam pasto para o gado; alimentavam os animais; tiravam leite; buscavam lenha; faziam as tarefas domésticas. Era um contexto de vida que lhes colocava na posição de trabalhadores desde a mais tenra idade.

\section{Trabalho, cultura, educação e infância}

$\mathrm{O}$ trabalho infantil na vitivinicultura de Videira se relaciona à necessidade de a criança contribuir para a sobrevivência familiar, bem como à educação das gerações futuras, que 
devem desde cedo aprender a amar o trabalho e a se tornar produtivas. Thompson (1987) percebeu que, durante a ascensão do sistema capitalista, os trabalhadores foram induzidos a amar o trabalho por intermédio da educação, da religião, de punições físicas ou mesmo porque era a única possibilidade de sobrevivência. O poder transformador da cruz, conforme os relatos do autor, condicionava o reino dos céus apenas aos trabalhadores. O sofrimento terreno, diretamente ligado à labuta em péssimas condições, seria compensado com uma eternidade no paraíso. Em contrapartida, a "vagabundagem" era passível do que seria a pior de todas as punições: a danação eterna. Assim, construiu-se e se perpetuou a imagem social de que o indivíduo bom e virtuoso é aquele que trabalha e é produtivo.

Sobre a educação formal, a partir de Marx (2017), evidencia-se que o surgimento da escola teve ligação direta com o desenvolvimento da indústria moderna, durante a Revolução Industrial. Se a maquinaria permitiu a exploração da força de trabalho infantil em longas jornadas, também contribuiu para o acirramento da luta de classe. Os trabalhadores passaram a lutar sistematicamente por melhores condições de trabalho para seus filhos e por redução de suas jornadas. Como conquista desses movimentos, mas também como concessão da classe burguesa - pela fragilidade da saúde dos trabalhadores adultos expostos precocemente ao trabalho insalubre -, foram criadas as leis fabris, a partir de 1840. Tal legislação limitou as jornadas de crianças e adolescentes e os proibiu de desempenhar funções perigosas e noturnas, da mesma forma que tornou obrigatória a frequência escolar.

Um reflexo contraditório das leis fabris foi a retirada gradativa das crianças do trabalho nas fábricas e o seu deslocamento para espaços privados, nos quais permaneciam trabalhando, escamoteadas sob relações familiares e de difícil fiscalização. Evidencia-se que as leis fabris que criaram obrigatoriedades escolares para as crianças, no entanto, não as retiraram do trabalho, ainda que tenham se constituído como os primeiros anúncios de proteção da infância contra a exploração de sua força de trabalho (CONDE, 2012).

Para Mészáros (2008), a educação escolar se constituiu historicamente tendo duas grandes finalidades: reproduzir no indivíduo as mínimas qualidades necessárias à formação de um bom trabalhador para o mercado; e transmitir a interiorização de um quadro de valores visando à legitimação dos interesses da classe dominante.

No Brasil, as transformações no mundo do trabalho também implicaram diretamente o desenvolvimento da educação institucionalizada. Com a adoção do trabalho juridicamente 
livre - relação social específica do capitalismo -, surgiu a necessidade de instituir um sistema de formação de trabalhadores, tanto para prover a qualificação requerida quanto para formar o novo cidadão, fruto das novas relações sociais que emergiam (FIOD, 2008). Especificamente em Videira, SC, a constituição da escola pública foi um processo lento, que, no começo, dependeu muito mais de iniciativas individuais do que do Estado. Segundo o Museu do Vinho Mário de Pellegrin (2014), ao longo da década de 1920, a educação formal dependia das iniciativas isoladas de duas professoras, que ensinavam em casa e na igreja local. Em 1934, ambas foram unificadas em um Grupo Escolar, dando origem à primeira escola pública da localidade. Antes disso, em 1933, já havia sido instalada uma escola particular de cunho religioso, pleiteada pelo dono de uma companhia colonizadora e por um grande vitivinicultor.

As referidas escolas localizavam-se na área urbana e não alcançavam a população rural, devido à distância e à precariedade dos meios de transporte e do sistema viário. Nas zonas rurais, eram as próprias famílias quem organizavam a educação formal das crianças, por vezes contando com o apoio de instituições religiosas. Baldissera et al. (2016) pontuam que as crianças eram alfabetizadas e aprendiam rudimentos de matemática em casa, tendo como mediador algum vizinho voluntário que dominasse tais saberes. Porém, tão logo conseguia se organizar, a comunidade construía salas de aula e as mantinha até que o Poder Público se dispusesse a tutelá-las - o que passou a ocorrer a partir de 1930, por meio da criação de escolas multisseriadas.

Nenhum dos participantes desta pesquisa teve um percurso escolar longo. Entre as mulheres, duas concluíram apenas o primário, outra não frequentou escola "nem um minutinho" na sua vida (informação oral). ${ }^{3}$ Não por coincidência, tratava-se da mais velha, de 102 anos. Quando ela migrou para a região com a sua família, em 1920, não havia escolas próximas o suficiente para ela frequentar. Já entre os homens, os três estudaram por pelo menos um ano na zona urbana, apesar de também não terem concluído o ginasial e o colegial.

De forma geral, as crianças iam a pé e descalças para a escola, que ficava na sede da comunidade, a uma distância de dois a quatro quilômetros de suas residências. Para um observador desavisado, andar com os pés diretamente na terra pode parecer um elemento cultural daquele grupo de indivíduos. Todavia, a situação era reflexo da materialidade vivida, calcada na pobreza e na ausência de recursos. 
Acerca do trajeto entre casa e escola, uma entrevistada revelou a necessidade de conduzir os irmãos menores até à aula. O caminho a ser percorrido era deserto e oferecia risco de encontro com o gado solto. A participante era a irmã mais velha, portanto era sua responsabilidade acompanhar os menores às aulas diariamente. Isso a fez ir para a escola por mais tempo que os irmãos: como a escola ofertava apenas o primário, ela repetiu quatro vezes o quarto ano, mesmo sem reprovações. Aos 14 anos, deixou de ir às aulas, porque, além dos irmãos terem crescido, era considerado vergonhoso ir à escola naquela idade, segundo ela própria.

No período contrário às aulas, as crianças tinham responsabilidades de trabalho, que envolviam o cuidado com os irmãos, as tarefas domésticas, o manejo de animais e o cultivo das roças. Outra participante pontuou que suas responsabilidades no contraturno definiam como ela se deslocava para a escola, evidenciando a relação entre trabalho, cultura e infância:

\footnotetext{
Até, inclusive, [...], nós que fomos na escola, na aula lá na colônia, a gente ia a cavalo, pra gente chegar em casa mais descansado, pra depois, o outro meio dia, ajudar o pai e a mãe na roça. O pai tinha cavalo bom. Então a gente ia pra escola rápido, porque daí ia a galope. Não tinha carro que passava nas estradas. Então você saía a galope. Dava o quê? Quatro quilômetros e pouco, por aí. E a gente ia pra escola, parava o cavalo lá, estudava e, de meio-dia, pegava o cavalo, num instante estava em casa. Sempre que eu estudei, eu fui a cavalo. (informação oral). ${ }^{4}$
}

Ir para as aulas cavalgando era um modo de preservar sua força de trabalho para as atividades da tarde. Ainda que seja o único depoimento que denote este tipo de preocupação, o trabalho era um denominador comum no contraturno de todos os entrevistados: "nas horas que estava em casa, tinha que ajudar" (informação oral) ${ }^{5}$. E, quando se diz ajuda, leia-se trabalho: "ajudar a tirar leite", "ajudar na roça", "ajudar a limpar a casa". Além de potencialmente ser um reflexo do olhar atual sobre um fato do passado - característico da memória -, essa forma de interpretar o trabalho se relaciona ao fato de que as crianças sempre trabalhavam sob a tutela dos pais. Elas trabalhavam coletivamente, com todos os membros da família, 'ajudando'. Porém a ajuda se configurava como trabalho, porque as crianças tinham suas próprias responsabilidades laborais, independentemente de suas vontades. O trabalho das crianças relacionava-se à sobrevivência do núcleo familiar, já que era necessário produzir para o mercado e para a própria subsistência, sem máquinas disponíveis para tal. Então, as crianças "faziam os mais leves" (informação oral) ${ }^{4}$ - no caso, os trabalhos mais leves. 
Em síntese, no contraturno da escola havia uma rotina de trabalho constante para as crianças na pequena propriedade familiar. Quem estudava de manhã, trabalhava de tarde, e vice-versa. $\mathrm{Na}$ intersecção com a escola, o trabalho foi citado como a razão para que alguns entrevistados interrompessem seus estudos.

A escola oferecia às crianças apenas rudimentos dos conhecimentos necessários à reprodução de si como pequenos agricultores, tais quais seus pais. São exemplos: noções básicas de matemática, ciências, leitura e escrita - além do civismo e da moralidade, próprios da formação de indivíduos disciplinados para trabalharem em relações capitalistas. $\mathrm{O}$ trabalho em si era aprendido na prática, desde pequenos, ao acompanharem os pais e irmãos mais velhos e ao assumirem, gradativamente, tarefas na divisão familiar do trabalho. Isso quer dizer que a família era o meio em que os indivíduos se reproduziam como membros do gênero humano pertencentes a uma sociedade e, portanto, onde aprendiam seus direitos e deveres e os comportamentos socialmente esperados.

Dos seis entrevistados, quatro relataram que suas brincadeiras tinham um momento semanal determinado: ocorriam aos domingos, pois, nos demais dias, tinham seu tempo ocupado pelo trabalho e pela escola. Por isso, os participantes não rememoraram situações de brincar sob o parreiral, "[...] porque, se ia para a parreira durante a semana, era pra trabalhar" (informação oral)1. Outra participante relatou que, "na roça, nunca que a gente brincava. Era só trabalhar. Brincar era só nos dias de domingo, quando a gente ficava em casa" (informação oral) ${ }^{3}$. De modo geral, na infância dos participantes desta pesquisa, o brincar era suprimido pela atividade de trabalho, que tomava todo o tempo daquelas crianças; exceto no domingo.

Da mesma forma como a Igreja associava o trabalho à virtude (THOMPSON, 1987), ela também assegurava a existência de um dia de ócio para a reposição da força de trabalho, que voltaria a ser intensamente utilizada no dia seguinte. Porém ambas as posições da Igreja repercutiam diretamente sobre as crianças: se o trabalho é uma virtude, então é bom, portanto as crianças não devem ser poupadas dele, mas sim estimuladas desde cedo; a folga dominical, por sua vez, representava a única oportunidade para o livre brincar.

É importante ressaltar que a valorização do trabalho fazia parte do contexto cultural dos ítalo-descendentes, como uma espécie de 'cultura do trabalho'. Para os estudiosos da Teoria Histórico-Cultural (LEONTIEV, 1978), os indivíduos se tornam propriamente 
humanos com a aquisição de habilidades, como as funções psicológicas superiores, a partir da interação com o meio cultural em que estão inseridos. Dentro dessa perspectiva, a cultura tem seu significado relacionado ao aparato de saberes (teóricos, artísticos, simbólicos, filosóficos, científicos) produzidos pela humanidade, que condicionam as formas de ser e viver no mundo. A cultura apresenta um vínculo estreito com a classe social, sendo pouco comum, por exemplo, a cultura do trabalho entre jovens e adolescentes de famílias ricas, mas frequente e rotineira entre jovens e adolescentes da classe trabalhadora. Em todos os casos, é evidente que a cultura não é dada a priori, como uma característica inata, mas se constitui nas relações sociais, estando em constante transformação e, portanto, passível de mudança a partir das intencionalidades humanas. Logo, se o trabalho infantil é parte da cultura entre descendentes ítalo-brasileiros, ele pode deixar de ser à medida que as relações sociais são transformadas e a exploração ou 'ajuda' das crianças deixa de ser uma necessidade.

Por fim, ressaltamos que a análise do trabalho infantil sob uma perspectiva cultural está expressa em diferentes trabalhos (OSTETTO, 1997; PRADO, 2013; STROPASSOLAS, 2012), que apontam fatores culturais como determinantes para a persistência do fenômeno no campo até a atualidade. Tais autores, ao não reconhecerem a cultura como produto da forma de vida e criação humana, acabam por naturalizar e cristalizar o trabalho precoce, entendido como mais uma das diferenças culturais a serem respeitadas dentro das abordagens relativistas da verdade. Assim, preserva-se aquilo que, a princípio, tem que ser transformado. Ainda que pese a necessidade de reconhecimento da diversidade cultural que compõe o vasto território brasileiro e planetário, o respeito à cultura do trabalho infantil implica a naturalização do fato de que um grupo social deve trabalhar enquanto outro deve estudar e desfrutar das virtudes das artes, da música, da boa comida, da boa vestimenta, da literatura, das línguas, da ciência etc.

\section{Considerações Finais}

Os dados da pesquisa evidenciam que as crianças estavam inseridas nas mais diversas fases da produção da uva, no bojo da propriedade familiar ou até mesmo fora desta, na propriedade de terceiros. Naquele contexto de relações, onde estava o trabalho dos pais, lá estava também o das crianças. O trabalho era prioridade, competia com o tempo de estudos e com o tempo de brincar. Havia a necessidade de que a criança contribuísse com o trabalho 
familiar, além de uma cultura religiosa e moral de valorização do trabalho infantil desde a tenra idade. Juntamente com esses fatores, a ausência de escolas e a dificuldade de acessá-las no meio rural culminaram no fato de que a totalidade de nossos entrevistados não ultrapassou o ensino primário.

Com isso, percebemos que a cultura da uva e do vinho no Sul, considerado popularmente como uma 'maravilha' do território brasileiro, traz em seu bojo o suor e o sangue de crianças que trabalharam desde cedo, sofreram com as intempéries climáticas e com os acidentes de trabalho. Se o trabalho ainda é visto como expressão da diversidade cultural e elemento educativo para as novas gerações, dialeticamente, os depoimentos reconhecem que ele é como veneno e "deixou todo mundo meio torto". Por conta de sua necessidade, somada às longínquas distâncias entre os centros rurais e urbanos, as crianças não puderam continuar com os estudos.

Embora, para Vygotsky (1991), a atividade de brincar tenha papel fundamental no desenvolvimento humano, haja vista que, por meio dela, a criança se utiliza do imaginário para transpor o significado de um objeto, de uma relação ou até mesmo para satisfazer um desejo, na vida das famílias vitivinicultoras de Videira, a brincadeira foi uma exceção. As crianças trabalhavam muito mais do que brincavam. Assim, o trabalho assumia caráter de atividade mediadora entre a criança e o mundo, tornando-se um meio de humanização ambíguo e limitado, tendo em vista o contexto desumanizador do trabalho na sociedade capitalista, que se pauta na exploração, na simplificação, na alienação e na fragmentação. Assim, as crianças submetidas ao trabalho nesse modo de sociabilidade também eram submetidas a um "desenvolvimento distorcido do potencial humano" (VYGOTSKY, 2004).

\section{Referências}

BALDISSERA, D. et al. Memórias em tempos de mudanças. Joinville: Clube dos Autores, 2016. 106 p.

BOSI, E. Memória e Sociedade: lembranças de velhos. 9. ed. São Paulo: Companhia das Letras, 1994.

CASTRO, V. L. S. S. de. Uso de misturas de agrotóxicos na agricultura e suas implicações toxicológicas na saúde. Journal Of The Brazilian Society Of Ecotoxicology, [S. l.], v. 4, n. 1-3, p. 87-94, 2009. Ecototoxicology and Environmental Contamination. DOI: 
http://dx.doi.org/10.5132/jbse.2009.01.012. Disponível em: https://bit.ly/2QoPDtx. Acesso em: $1^{\circ}$ maio 2019.

CONDE, S. F. A escola e a exploração do trabalho infantil na fumicultura catarinense. 2012. 190 f. Tese (Doutorado em Educação) - Programa de Pós-graduação em Educação, Universidade Federal de Santa Catarina, Florianópolis, 2012. Disponível em: https://bit.ly/3tCN717. Acesso em: 24 ago. 2018.

FIOD, E. G. M. Escola e Trabalho: forças que resistem no tempo. Florianópolis: Insular, 2008. $224 \mathrm{p}$.

HOELLER, M. L. dal B.; ZAGO, D.; SINZKER, R. C. Pioneiros da Uva e do Vinho. Videira: Exito, 2018. 370 p.

KARAN, F. Memórias de um médico do interior. 2. ed. Florianópolis: Insular, 2000. 160 p.

LEONTIEV, A. O homem e a cultura. In: LEONTIEV, A. O desenvolvimento do psiquismo. Lisboa: Horizonte, 1978. p. 261-284. Disponível em: https://bit.ly/2Ny4HUx. Acesso em: 5 jun. 2019.

MARX, K. O Capital: crítica da Economia Política. 2. ed. São Paulo: Boitempo, 2017. 894 p. (Coleção Marx). Publicado originalmente em 1867.

MÉSZÁROS, I. A educação para além do capital. 2. ed. São Paulo: Boitempo, 2008.

MUSEU DO VINHO MÁRIO DE PELLEGRIN. Exposição de Longa Duração. Videira, 2014.

OSTETTO, L. C. Vozes que recitam, lembranças que se refazem: narrativas de descendentes italianas/os. Nova Veneza - 1920-1950. 1997. 192 f. Dissertação (Mestrado em História) Programa de Pós-Graduação em História, Universidade Federal de Santa Catarina, Florianópolis, 1997. Disponível em: https://bit.ly/3s59GuT. Acesso em: 30 jul. 2018.

POLLAK, M. Memória e identidade social. Estudos Históricos, Rio de Janeiro, v. 5, n. 10, p. 200-212, 1992. Disponível em: https://bit.ly/3vFclh7. Acesso em: 10 dez. 2018.

PRADO, E. M. O infausto cotidiano dos pequenos ítalo-brasileiros em um antigo núcleo colonial no princípio do século XX. Cadernos de História da Educação, Uberlândia, v. 12, n. 2, p. 483-502, dez. 2013. Disponível em: https://bit.ly/3vJIPXu. Acesso em: 30 jul. 2018.

RODRIGUES, C. H. M. Vida Difícil na “Terra de Baco”: a Questão Agrária na Microrregião vinicultora de Caxias do Sul e o caso dos vitivinicultores familiares (1880-1930). 2008. $149 \mathrm{f}$. Dissertação (Mestrado em História) - Programa de Pós-Graduação em História, Universidade do Estado do Rio de Janeiro, São Gonçalo, 2008. Disponível em: https://bit.ly/30ZOJ8Y. Acesso em: 30 jul. 2018.

SANTOS, J. M. P. História da família de Dosolina Binotto e Eugênio Menegazzo. Curitiba: Via Laser Gráfica e Editora, 2012. 124 p. 
SILVA, J. M. da et al. Agrotóxico e trabalho: uma combinação perigosa para a saúde do trabalhador rural. Ciência \& Saúde Coletiva, Rio de Janeiro, v. 10, n. 4, p. 891-903, dez. 2005. DOI: http://dx.doi.org/10.1590/s1413-81232005000400013. Disponível em: https://bit.ly/2Qim9gN. Acesso em: $1^{\circ}$ maio 2019.

STANDAGE, T. História do mundo em 6 copos. Rio de Janeiro: Zahar, 2005.

STROPASOLAS, V. L. Trabalho infantil no campo: do problema social ao objeto sociológico. Revista Latino-americana de Estudos do Trabalho, Buenos Aires, v. 17, n. 27, p. 249-286, out. 2012. Semestral. Disponível em: https://bit.ly/3c0HeVj. Acesso em: 24 ago. 2018.

THOMPSON, E. P. A formação da classe operária inglesa II: a maldição de Adão. Rio de Janeiro: Paz e Terra, 1987. 345 p. (Coleção Oficinas da História).

VENENO. In: DICIO, Dicionário Online de Português. Porto: 7 Graus, 2018. Disponível em: https://www.dicio.com.br/veneno/. Acesso em: 10 abr. 2019.

VYGOTSKI, L. S. A formação social da mente. 4. ed. São Paulo: Martins Fontes, 1991.

VYGOTSKY, L. S. A Transformação Socialista do Homem. [S. l.]: Marxists Internet Archive, 2004. Escrito em 1930. Disponível em: https://bit.ly/3f0YHir. Acesso em: 28 ago. 2018.

\footnotetext{
Notas

1. Entrevista concedida à Natalia Palhoza em 9 dez. 2018.

2. Entrevista concedida à Natalia Palhoza em 12 dez. 2018.

3. Entrevista concedida à Natalia Palhoza em 4 ago. 2018.

4. Entrevista concedida à Natalia Palhoza em 20 dez. 2018.

5. Entrevista concedida à Natalia Palhoza em 7 dez. 2018.
} 